\title{
Signaling Cascade Regulating Long-Term Potentiation of GABA Receptor Responsiveness in Cerebellar Purkinje Neurons
}

\author{
Shin-ya Kawaguchi and Tomoo Hirano \\ Department of Biophysics, Graduate School of Science, Kyoto University, Sakyo-ku, Kyoto 606-8502, Japan, and \\ Core Research for Evolutional Science and Technology, Japan Science and Technology Corporation, Kawaguchi, \\ Saitama 332-0012, Japan
}

Synaptic plasticity, a cellular basis of learning and memory, has been studied extensively at excitatory synapses. Although synaptic plasticity has also been reported at inhibitory synapses, the molecular mechanism remains elusive. Here we attempted to clarify the overall signaling cascades regulating the induction of inhibitory synaptic plasticity in the cerebellum.

Rebound potentiation (RP), a long-lasting increase in $\mathrm{GABA}_{\mathrm{A}}$ receptor $\left(G A B A_{A} R\right)$ responsiveness, is induced by postsynaptic depolarization of a Purkinje neuron (PN) at synapses formed with inhibitory interneurons (stellate or basket neurons). Previously, we showed that RP is suppressed by homosynaptic activation during depolarization through activation of the postsynaptic $G_{A B A}$ receptor $\left(G A B A_{B} R\right)$. Activation of $G A B A_{B} R$ reduces cAMP-dependent protein kinase (PKA) activity via the $G_{i} / G_{0}$ protein. Here we examined the molecular pathway through which PKA activity affects RP induction.

Synaptic plasticity, a cellular analog of learning and memory, has been studied extensively at excitatory synapses (Malenka, 1994; Malenka and Nicoll, 1999; Ito, 2001; Lisman and Zhabotinsky, 2001). Although synaptic plasticity at inhibitory synapses has also been reported (Kano et al., 1992; Komatsu, 1996; Nusser et al., 1998; Oda et al., 1998), relatively little is known about the molecular mechanisms of its induction, despite the pivotal role of inhibitory synaptic transmission in the CNS.

Rebound potentiation (RP), a long-lasting increase in $\mathrm{GABA}_{\mathrm{A}}$ receptor $\left(G_{A B A} R\right)$ responsiveness, is heterosynaptically induced by postsynaptic depolarization at GABAergic synapses between inhibitory interneurons (stellate or basket neurons) and Purkinje neurons (PNs) in the cerebellum (Kano et al., 1992). RP might play a role in motor learning (Kano, 1995; Hansel et al., 2001). It has been reported that the increase in intracellular $\mathrm{Ca}^{2+}$ concentration and subsequent activation of $\mathrm{Ca}^{2+} /$ calmodulindependent protein kinase II (CaMKII) are required for RP induction (Kano et al., 1992, 1996; Hashimoto et al., 1996). We have shown previously that there is a gating mechanism in RP (Kawaguchi and Hirano, 2000). Homosynaptic activation during depolarization suppresses RP through the activation of postsyn-

\footnotetext{
Received Oct. 15, 2001; revised Feb. 25, 2002; accepted Feb. 26, 2002.

This study was supported by grants from the Ministry of Education, Culture, Sports, Science and Technology, Japan to T.H. S.K. is a fellow of the Japan Society for the Promotion of Science. We thank Drs. R. Shigemoto, Y. Kubo, M. Kengaku, and M. M. Wu for comments on this manuscript.

Correspondence should be addressed to Tomoo Hirano, Department of Biophysics, Graduate School of Science, Kyoto University, Sakyo-ku, Kyoto 606-8502, Japan. E-mail: thirano@nb.biophys.kyoto-u.ac.jp.

Copyright (ㄷ) 2002 Society for Neuroscience $0270-6474 / 02 / 223969-08 \$ 15.00 / 0$
}

We confirmed that inhibition of $\mathrm{Ca}^{2+}$ /calmodulin-dependent protein kinase II (CaMKII) or PKA suppresses RP. We also found that inhibition of protein phosphatase 1 (PP-1) or calcineurin (PP-2B) impaired suppression of RP induction. Inhibition of either PP-1 or calcineurin abolished RP impairment by PKA inhibition, but not that by CaMKII inhibition. Antisense oligonucleotidemediated knock down of DARPP-32, which is a substrate of PKA and calcineurin and inhibits PP-1 when phosphorylated by PKA, suppressed RP. Furthermore, activation of $G_{A B A} R$ inhibited CaMKII activation through PKA inhibition and PP-1 activity. These results suggest that calcineurin activation accompanied by PKA inhibition in a PN causes dephosphorylation of DARPP-32, which releases PP-1 from inhibition. PP-1 in turn inhibits CaMKII activity, which is then directly involved in the RP induction.

Key words: synaptic plasticity; inhibitory synapse; GABA; Purkinje neuron; PP-1; calcineurin; DARPP-32; CaMKII; PKA

aptic $\mathrm{GABA}_{\mathrm{B}}$ receptor $\left(\mathrm{GABA}_{\mathrm{B}} \mathrm{R}\right)$. $\mathrm{GABA}_{\mathrm{B}} \mathrm{R}$ activation suppresses RP by reducing cAMP-dependent protein kinase (PKA) activity through the $G_{i} / G_{o}$-protein. This homosynaptic inputdependent suppression of RP induction might enable the inputspecific regulation of transmission efficacy at each inhibitory synapse on a PN (Kawaguchi and Hirano, 2000).

As mentioned above, both CaMKII and PKA have been implicated in RP induction; however, some questions remain to be answered. (1) What are the respective roles of CaMKII and PKA in RP induction? (2) How do CaMKII and PKA interact in a PN to regulate RP induction? The molecular mechanism regulating synaptic plasticity at an excitatory synapse provided a clue to answering these questions. In the hippocampal CA1 region, longterm potentiation (LTP) is induced by high-frequency stimulation of presynaptic fibers, and long-term depression (LTD) is induced by low-frequency stimulation. Although both LTP and LTD are triggered by an increase in intracellular $\mathrm{Ca}^{2+}$ concentration, the amount of the increase determines which is induced (Malenka, 1994; Malenka and Nicoll, 1999). A large increase in the $\mathrm{Ca}^{2+}$ concentration leads to CaMKII activation resulting in the LTP induction, whereas a small increase results in the augmentation of PP-1 activity, which counteracts CaMKII activity and thereby induces LTD (Malenka, 1994; Mulkey et al., 1994). Protein phosphatase 1 (PP-1) activity is regulated by PKA and calcineurin through Inhibitor-1 (I-1). We considered the possibility that PKA activity might also control CaMKII activity through a similar signaling cascade in a $\mathrm{PN}$, which might regulate RP induction. PNs do not express I-1 but they do express DARPP-32, a molecular homolog of I-1 (Hemmings et al., 1984; Schalling et al., 
1990). Thus, we examined individual roles and functional interactions of PP-1, calcineurin, CaMKII, PKA, and DARPP-32 in signaling pathways regulating RP induction. Here we present an entire framework of signaling cascades that regulates RP induction, which is similar to, but distinct from, that which regulates switching between LTP and LTD in the hippocampus.

\section{MATERIALS AND METHODS}

Culture. Primary cultures of cerebellar neurons from Wistar rats were prepared by the method described previously with slight modification (Hirano and Kasono, 1993). Briefly, cerebella were dissected from fetuses at approximately day 18 of gestation. After the meninges were removed, cerebella were incubated in $\mathrm{Ca}^{2+}$ - and $\mathrm{Mg}^{2+}$-free HBSS containing $0.1 \%$ trypsin and $0.05 \%$ DNase for $15 \mathrm{~min}$ at $37^{\circ} \mathrm{C}$. Cells were then dissociated by trituration and cultured in a defined medium for $>4$ weeks. Half of the culture medium was changed every $4 \mathrm{~d}$.

Electrophysiology. Whole-cell patch-clamp recordings from cerebellar PNs grown in culture for 4-6 weeks were performed in a solution containing (in mM): $145 \mathrm{NaCl}, 5 \mathrm{KOH}, 2 \mathrm{CaCl}_{2}, 1 \mathrm{MgCl}_{2}, 10$ HEPES, and 10 glucose, $\mathrm{pH} 7.3$, at room temperature $\left(20-24^{\circ} \mathrm{C}\right)$. The external solution contained $10 \mu \mathrm{M}$ 6-cyano-7-nitroquinoxaline-2, 3-dione (CNQX; Tocris, Bristol, UK) to suppress glutamatergic EPSCs and $1 \mu \mathrm{M}$ tetrodotoxin (TTX; Wako, Osaka, Japan) to suppress action potentials. Patch pipettes used to record from PNs were filled with an internal solution containing (in mM): $150 \mathrm{CsCl}, 7 \mathrm{CsOH}, 0.5$ EGTA, 10 HEPES, 2 Mg-ATP (Sigma, St. Louis, MO), and 0.2 Na-GTP (Sigma), pH 7.3. Mg-ATP and Na-GTP were used to minimize the rundown of GABA $_{A}$ responsiveness. The electrode resistance was 3-5 M $\Omega$. The membrane potential of a PN was held at $-70 \mathrm{mV}$ unless stated otherwise. Junction potentials were offset. At this potential and with the internal solution containing $150 \mathrm{mM} \mathrm{Cl}^{-}$, GABA responses were recorded as inward currents. Only recordings with an input resistance of $>100 \mathrm{M} \Omega$ and series resistance of $<30 \mathrm{M} \Omega$ were accepted for analysis. Series resistance and input resistance were monitored every $3 \mathrm{~min}$, and experiments were terminated when a change of $>20 \%$ was detected. The method used for iontophoretic application of GABA was similar to previous studies (Kawaguchi and Hirano, 2000). A glass pipette containing $10 \mathrm{~mm}$ GABA with $10 \mathrm{mM}$ HEPES was aimed at a proximal or a secondary dendrite of a PN, and $20 \mathrm{msec}$ positive voltage pulses were applied every minute. The conditioning depolarizations of a PN were five $500 \mathrm{msec}$ pulses to $0 \mathrm{mV}$ at $0.5 \mathrm{~Hz}$. Iontophoretic application of GABA coupled with the depolarizations was given $100 \mathrm{msec}$ after the onset of each $500 \mathrm{msec}$ depolarization pulse. GABA was not applied during uncoupled depolarizations. Data are presented as mean \pm SEM unless stated otherwise. Baclofen (Tocris; $20 \mu \mathrm{M}$ ), SCH50911 (Tocris; $10 \mu \mathrm{M}$ ), forskolin (Tocris; $20 \mu \mathrm{M})$, KT5720 (Calbiochem, San Diego, CA; $10 \mu \mathrm{M})$, nodularin (Calbiochem; $2 \mathrm{~nm}$ ), okadaic acid (Tocris; 1 or $100 \mathrm{~nm}$ ), or KN62 (Calbiochem; $5 \mu \mathrm{M}$ ) was applied to the bath. Peptides (purity $>92 \%$ ) were obtained from Kurabo Co. (Osaka, Japan). The peptides $(5 \mu \mathrm{M})$ or FK506 (Calbiochem; $100 \mathrm{nM}$ ) were included in the internal solution. Oligonucleotide (ODN) (purity $>95 \%$ ) was obtained from Amersham Biosciences (Buckinghamshire, UK). We used an ODN $(3 \mu \mathrm{M})$ against nucleotides 48-67 from the initiation codon of the rat DARPP-32 mRNA (Ehrlich et al., 1990). ODNs contained phosphorothioate linkages on the three terminal bases of both the $5^{\prime}$ and $3^{\prime}$ ends. The antisense and the missense ODN sequences used were 5'-GGGGGTCGAGCTGGCTCGGG-3' and 5'AGGGGGGGGGCTCGGCGCTT-3', respectively.

Western blot analysis. Protein samples were prepared from neurons cultured at the same time. Neurons were boiled in 1\% SDS and sonicated in the sample buffer for $5 \mathrm{~min}$. Fifty micrograms of protein were extended in $12 \%$ polyacrylamide gel by SDS-PAGE and transferred to nitrocellulose membrane. After incubating the membrane in the PBS containing rabbit anti-DARPP-32 antibody (1:1000; Chemicon, Temecula, CA) followed by incubation in PBS containing HRP-conjugated goat anti-rabbit IgG antibody (1:5000; Chemicon), the signals were detected using the ECL kit (Amersham Biosciences). Then antibodies were removed using Re-blot Plus (Chemicon). Calbindin was probed with rabbit anticalbindin D-28 primary antibody (1:1000; Chemicon) and HRPconjugated anti-rabbit IgG secondary goat antibody. The densitometry of each signal was performed using Scion Image PC software.

Immunocytochemistry. To monitor active CaMKII, cultured cerebellar neurons treated for $2 \mathrm{~min}$ in the test medium were replaced in the external solution for 3 min before fixation with $4 \%$ paraformaldehyde. Fixed preparations were permeabilized in Tris-buffered saline containing
$0.5 \%$ Tween and $2 \%$ skim milk and labeled with primary antibodies followed by staining with secondary antibodies. Primary and secondary antibodies used were as follows: rabbit polyclonal antibody $(\mathrm{pAb})$ against Thr286-phosphorylated CaM KII (1:1000; Promega, Madison, WI), pAb against calbindin D28 (1:500; Chemicon), mouse monoclonal antibody $(\mathrm{mAb})$ against $\alpha \mathrm{CaMKII}$ (1:500; Chemicon), mAb against calbindin D28 (1:200; Sigma), Alexa 568-conjugated pAb against rabbit IgG (Molecular Probes, Eugene, OR), Alexa 488-conjugated pAb against mouse IgG (Molecular Probes), Alexa 568-conjugated pAb against mouse IgG (Molecular Probes), and Alexa 488-conjugated pAb against rabbit IgG (Molecular Probes). Fluorescent images were obtained with a confocal laser microscope (CSU 10; Yokogawa Electric Corporation, Musashino, Japan) mounted on an upright microscope (Eclipse E800, Nikon, Tokyo, Japan), and analyzed using IPLab software (Solution Systems, Funabashi, Japan). To compare quantitatively the amount of active CaMKII, the average immunofluorescent signal of Thr286-phosphorylated CaMKII in a PN was used. First the total fluorescence intensity of Thr286-phosphorylated CaMKII within a PN was measured and then divided by the area of the PN. PNs were identified as calbindin-positive regions in the visual field. Calbindin is distributed throughout PNs but not in other cells in the culture. At least 19 PNs were measured in each test medium.

\section{RESULTS}

\section{PP-1 is required for RP suppression}

Whole-cell voltage-clamp recording from cultured cerebellar PNs was performed. As reported previously, RP is expressed as an increase in $\mathrm{GABA}_{\mathrm{A}} \mathrm{R}$ responsiveness (Kawaguchi and Hirano, 2000). We directly monitored $\mathrm{GABA}_{\mathrm{A}} \mathrm{R}$ responsiveness by recording GABA responses evoked by iontophoretic application of GABA to a proximal or a secondary dendrite of a PN. The GABA response was completely blocked by bicuculline, a $G_{A B A} R$ antagonist, indicating that the response is mediated by $G_{A B A} R$. Conditioning depolarization of a $\mathrm{PN}$ alone induced RP of the GABA response $(172 \pm 14 \%$ of the baseline amplitude; mean \pm $\mathrm{SEM} ; n=5$; at $30 \mathrm{~min}$ ), whereas conditioning depolarization coupled with GABA application suppressed RP as reported previously (94 $\pm 6 \%$ at $30 \mathrm{~min} ; n=5$; significant difference, $p<0.01$ ) (Fig. 1 $A, B$ ) (Kawaguchi and Hirano, 2000). In agreement with a previous study showing that CaMKII activity is required for RP induction (Kano et al., 1996), CaMKII inhibition by KN62 $(5 \mu \mathrm{M})$ impaired the induction of $\mathrm{RP}(91 \pm 8 \% ; n=5$; at $30 \mathrm{~min})$ (Fig. 1C).

To elucidate the molecular cascade responsible for suppressing RP induction, we first examined the role of PP-1, a phosphatase that opposes CaMKII activity (Strack et al., 1997). Nodularin, a PP-1 inhibitor, abolished the suppression of RP after the conditioning depolarization coupled with GABA application $(150 \pm$ $4 \%$ at $30 \mathrm{~min} ; n=5 ; p<0.001$ ) (Fig. $2 A-C)$. Okadaic acid (100 $\mathrm{nM})$, an inhibitor of PP-1 and PP-2A, also inhibited the suppression of RP $(183 \pm 10 \%$ at $30 \mathrm{~min} ; n=5 ; p<0.001$; data not shown). A lower concentration of okadaic acid $(1 \mathrm{nM})$ that is sufficient to inhibit PP-2A but not PP-1 had no effect on RP suppression (102 $\pm 7 \%$ at $30 \mathrm{~min} ; n=5$; data not shown). These results suggest that $\mathrm{PP}-1$, but not $\mathrm{PP}-2 \mathrm{~A}$, is necessary for the $\mathrm{GABA}_{\mathrm{B}} \mathrm{R}$-mediated suppression of RP. Neither nodularin nor okadaic acid affected the basal GABA response. We also examined effects of PP-1 inhibition on inhibitory synaptic responses by analyzing miniature IPSCs (mIPSCs). mIPSCs were recorded from PNs in the presence of TTX and CNQX. mIPSCs were completely abolished by bicuculline, indicating that they were mediated by $\mathrm{GABA}_{\mathrm{A}}$ Rs. The mean amplitudes, $10-90 \%$ rise time, half-height width, and frequency of mIPSCs were not affected by nodularin (Fig. 2D,E, Table 1). These results suggest that PP-1 inhibition by itself does not affect the properties of $\mathrm{GABA}_{\mathrm{A}}$ receptors in PNs. 


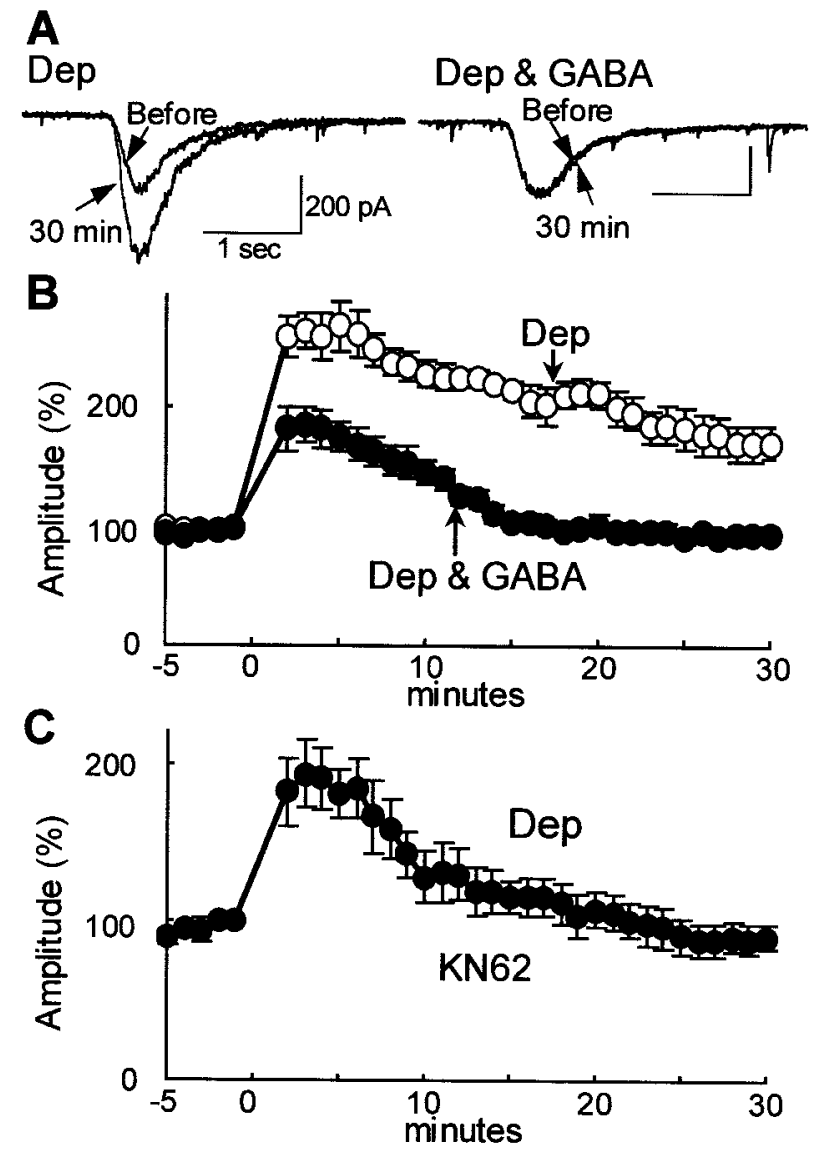

Figure 1. RP and its suppression. $A$, Representative GABA responses before and 30 min after the conditioning depolarization of a PN (Dep) alone or the conditioning depolarization coupled with GABA application (Dep \& $G A B A)$. B, C, Time courses of GABA response amplitude before and after the conditionings. Each conditioning was applied at $0 \mathrm{~min}$. GABA response amplitude was normalized. The value at -1 min was assigned to $100 \%$. $n=5$ for each. $B$, Depolarization alone $(\bigcirc)$ or depolarization coupled with GABA application $(\bullet)$ was given as a conditioning. $C$, Depolarization was given as a conditioning in the presence of KN62.

\section{CaMKII plays a more direct role in RP induction than PKA}

Previous studies showed that both PKA and CaMKII activity are required for RP induction (Kano et al., 1996; Kawaguchi and Hirano, 2000). It was also reported that application of 8-bromocAMP increases the GABA-mediated current in PNs (Kano and Konnerth, 1992). We confirmed that KT5720 and KN62, respective inhibitors of PKA and CaMKII, blocked RP induction (Figs. $1 C, 3 A, \bigcirc)$. Neither KT5720 nor KN62 affected the basal GABA response (data not shown), amplitude, time course, or frequency of mIPSCs (Table 1).

We next attempted to clarify the functional interactions of PP-1 with CaMKII and PKA. We examined the effects of combined application of KT5720 or KN62 with a PP-1 inhibitor nodularin on RP induction. Inhibition of PP-1 by nodularin opposed the suppression of RP by KT5720 (172 $\pm 11 \%$ at $30 \mathrm{~min}$; $n=5 ; p<0.001$ ) (Fig. $3 A, \bigcirc$ ), suggesting that the RP suppression by PKA inhibition is mediated by PP-1 activity. In contrast, nodularin had no effect on the RP suppression by KN62 (98 $\pm 7 \%$ at $30 \mathrm{~min} ; n=5$ ) (Fig. 3B). These results suggest that (1) PP-1 is activated downstream of PKA inhibition and leads to RP sup-
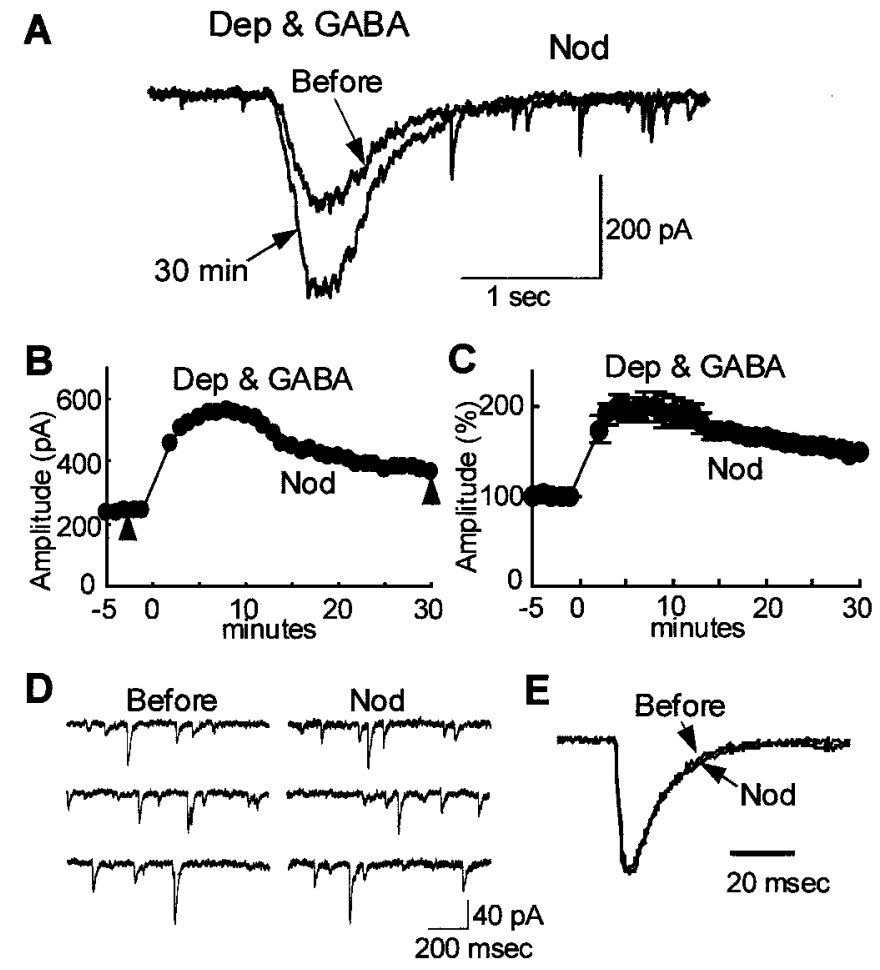

Figure 2. Involvement of PP-1 in RP suppression. $A$, Representative GABA responses before and $30 \mathrm{~min}$ after the conditioning depolarization coupled with GABA application in the presence of nodularin (Nod). B, A representative time course of GABA response amplitude from a PN before and after the conditioning depolarization coupled with GABA application in the presence of nodularin. Arrows indicate the time points when traces shown in $A$ were recorded. $C$, Normalized time course of GABA response amplitude averaged across five independent trials. Same conditions as in B. D, Representative mIPSCs before and $15 \mathrm{~min}$ after the application of nodularin. $E$, Averaged and scaled mIPSC traces $(n=20)$ before and $15 \mathrm{~min}$ after the nodularin application.

pression and (2) CaMKII activity inducing RP is downstream of PP-1 activity. Thus, CaMKII is more directly involved in RP induction than PKA.

\section{Calcineurin is required for RP suppression}

It has been reported that CaMKII and calcineurin/I-1/PP-1 pathways are involved in the regulation of hippocampal LTP and LTD (Malenka, 1994; Mulkey et al., 1994). I-1 directly inhibits PP-1 when phosphorylated by PKA (Ingebritsen and Cohen, 1983). Calcineurin, which is activated by an increase in intracellular $\mathrm{Ca}^{2+}$ concentration, dephosphorylates I-1 and releases PP-1 from inhibition (Malenka, 1994). We therefore examined the involvement of calcineurin in RP suppression. FK506, a calcineurin inhibitor, abolished RP suppression after the conditioning depolarization coupled with GABA application $(153 \pm 6 \%$ at 30 min; $n=5 ; p<0.001$ ) (Fig. 4A). FK506 did not affect the basal GABA response (data not shown), amplitude, time course, or frequency of mIPSCs (Table 1). These results suggest that besides PP-1, calcineurin is also required for $\mathrm{GABA}_{\mathrm{B}} \mathrm{R}$-mediated suppression of RP.

We then attempted to clarify the functional interaction of calcineurin and CaMKII or PKA. Calcineurin inhibition by FK506 countered the suppression of RP by PKA inhibition (KT5720 at $30 \mathrm{~min} ; 161 \pm 11 \% ; n=5 ; p<0.01$ ) (Fig. 4B). In contrast, calcineurin inhibition did not affect the suppression of RP by CaMKII inhibition (KN62 at $30 \mathrm{~min} ; 84 \pm 4 \%$; $n=5$ ) 
Table 1. Effects of pharmacological agents on amplitude, time course, and frequency of mIPSCs in PNs

\begin{tabular}{|c|c|c|c|c|c|c|c|c|}
\hline & \multicolumn{2}{|l|}{ Nodularin } & \multicolumn{2}{|l|}{ KN62 } & \multicolumn{2}{|l|}{ KT5720 } & \multicolumn{2}{|l|}{ FK506 } \\
\hline & Before & $15 \mathrm{~min}$ & Before & $15 \mathrm{~min}$ & Before & $15 \mathrm{~min}$ & Control & FK506 \\
\hline Amplitude (pA) & $13.9 \pm 3.3$ & $13.2 \pm 3.9$ & $11.7 \pm 2.2$ & $11.2 \pm 2.0$ & $10.4 \pm 2.3$ & $10.5 \pm 3.2$ & $15.2 \pm 3.0$ & $14.1 \pm 2.6$ \\
\hline $10-90 \%$ rise time $(\mathrm{msec})$ & $3.4 \pm 0.5$ & $3.0 \pm 0.5$ & $3.8 \pm 0.6$ & $3.9 \pm 0.4$ & $3.1 \pm 0.2$ & $3.0 \pm 0.5$ & $3.4 \pm 0.8$ & $3.4 \pm 0.5$ \\
\hline Half-height width (msec) & $16.2 \pm 2.6$ & $17.3 \pm 3.1$ & $20.0 \pm 1.9$ & $21.1 \pm 2.4$ & $17.2 \pm 0.8$ & $18.9 \pm 1.7$ & $16.7 \pm 3.1$ & $17.9 \pm 2.4$ \\
\hline Frequency $(\mathrm{Hz})$ & $9.7 \pm 2.2$ & $8.8 \pm 3.4$ & $12.0 \pm 3.2$ & $12.6 \pm 8.3$ & $9.4 \pm 2.0$ & $13.4 \pm 9.0$ & $10.7 \pm 4.2$ & $12.1 \pm 4.2$ \\
\hline
\end{tabular}

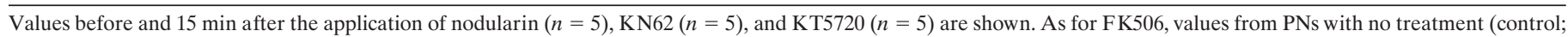
$n=13$ ) and those from PNs to which FK506 was introduced through a patch pipette (FK506; $n=11)$ are shown. Data are presented as mean \pm SD.
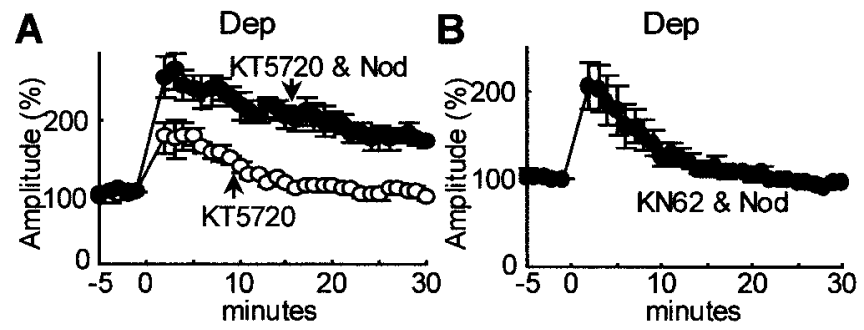

Figure 3. PP-1 inhibition restores RP induction suppressed by PKA inhibition but does not restore RP induction suppressed by CaMKII inhibition. Time courses of GABA response amplitude before and after the conditioning depolarization. $A$, Conditioning depolarization (Dep) in the presence of both nodularin (Nod) and KT5720 (-) or KT5720 alone $(\bigcirc) . B$, Conditioning depolarization in the presence of both nodularin and KN62.

(Fig. 4C). These results also support the idea that CaMKII is more directly involved in RP induction than PKA and suggest that the RP suppression by PKA inhibition is mediated not only by PP-1 but also by calcineurin.

\section{Involvement of DARPP-32 in RP induction}

The next obvious question to answer was which molecule mediates the interactions among PKA, calcineurin, and PP-1. Involvement of I-1, a native PP-1 inhibitor, in the switching of hippocampal synaptic plasticity prompted us to examine the role of an equivalent molecule in PNs. DARPP-32 is a homologous molecule to I-1 expressed in PNs (Hemmings et al., 1984; Schalling et al., 1990; Greengard et al., 1999). DARPP-32 directly inhibits PP-1 when phosphorylated at Thr34 by PKA. On the other hand, calcineurin releases PP-1 from inhibition by dephosphorylating DARPP-32. We considered that the regulation of PP-1 activity by PKA and calcineurin might be mediated by DARPP-32. Thus, we investigated the involvement of DARPP-32 in RP regulation directly by knocking down DARPP-32 expression using an antisense ODN. Incubation of cultured neurons with the antisense ODN for $8 \mathrm{hr}$ decreased the amount of DARPP-32 expressed, as revealed by Western blot analysis $(65 \pm 6 \% ; n=5)$, whereas the amount of calbindin, a molecular marker of PNs, was unchanged $(97 \pm 14 \%)$ (Fig. $5 A)$. In all of the antisense ODN-treated PNs examined, conditioning depolarization failed to induce RP (89 \pm $6 \%$ at $30 \mathrm{~min} ; n=5 ; p<0.01$ ) (Fig. $5 B$ ). Incubation with missense ODN affected neither the amount of DARPP-32 nor RP induction ( $156 \pm 5 \%$ at $30 \mathrm{~min} ; n=5)$ (Fig. $5 A, B)$. These results suggest that DARPP-32 acts as a positive regulator inducing RP, probably through the inhibition of PP-1 activity.

It has been reported that a number of proteins interacting with PP-1, including I-1 and DARPP-32, contain the KKIQF motif (Greengard et al., 1999). An N-terminal, 23 amino acid peptide of DARPP-32 containing the KKIQF motif, N'-MDPKGRKKI-
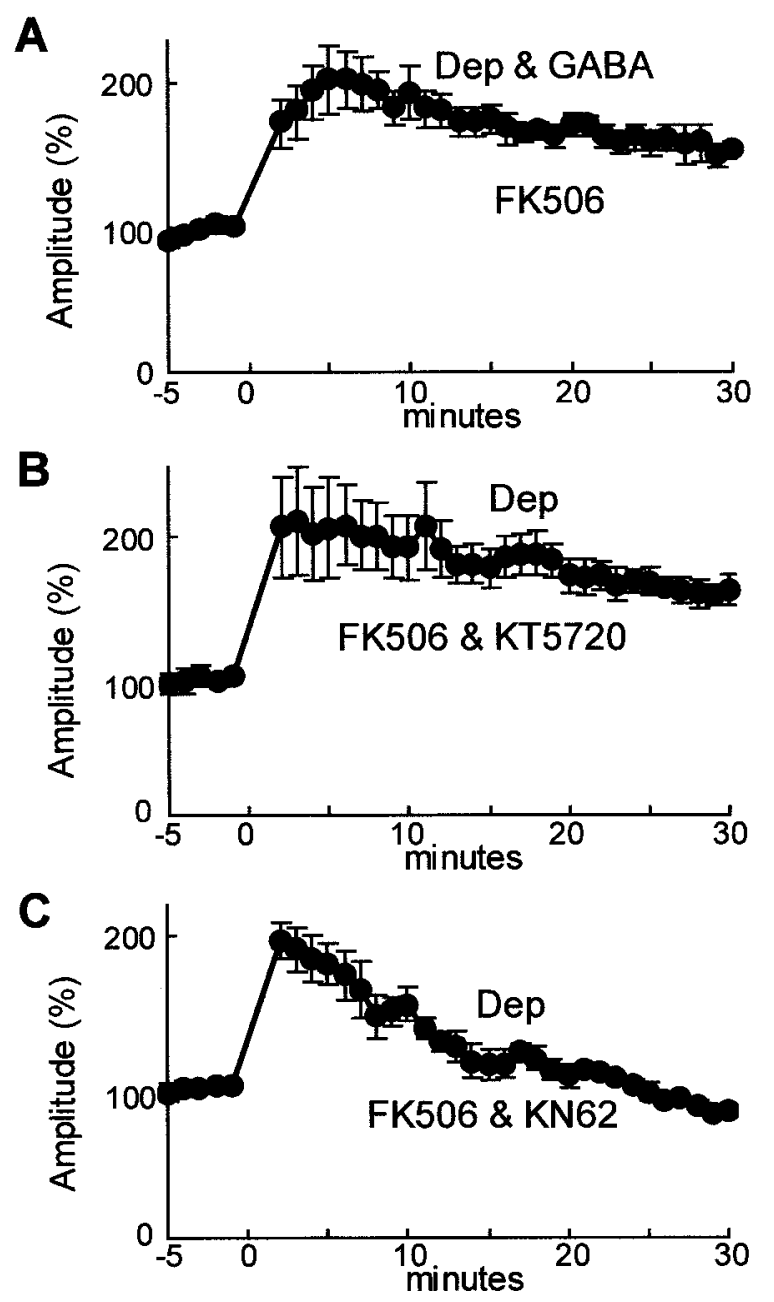

Figure 4. Involvement of calcineurin in RP suppression. Time courses of GABA response amplitude before and after conditionings. $A$, Conditioning depolarization coupled with GABA (Dep \& GABA) application applied in the presence of FK506 $(A) . B, C$, Conditioning depolarization $(D e p)$ applied in the presence of both FK506 and KT5720 (B) or of both FK506 and KN62 $(C) . n=5$ for each.

QFSVPAPPSQLDPC-C', competitively inhibits DARPP-32 binding to PP-1 and thereby releases PP-1 from suppression in vitro (Kwon et al., 1997). We attempted to investigate the effect of increasing PP-1 activity on RP induction using this peptide. Intracellular application of the peptide in a PN abolished RP induction ( $98 \pm 11 \%$ at $30 \mathrm{~min} ; n=5 ; p<0.01)$, whereas similar application of the control peptide in which the KKIQF motif was replaced with KETQY had no effect on RP induction $(165 \pm 7 \%$ at $30 \mathrm{~min} ; n=5$ ) (Fig. $5 C$ ). These results suggest that binding of 
A
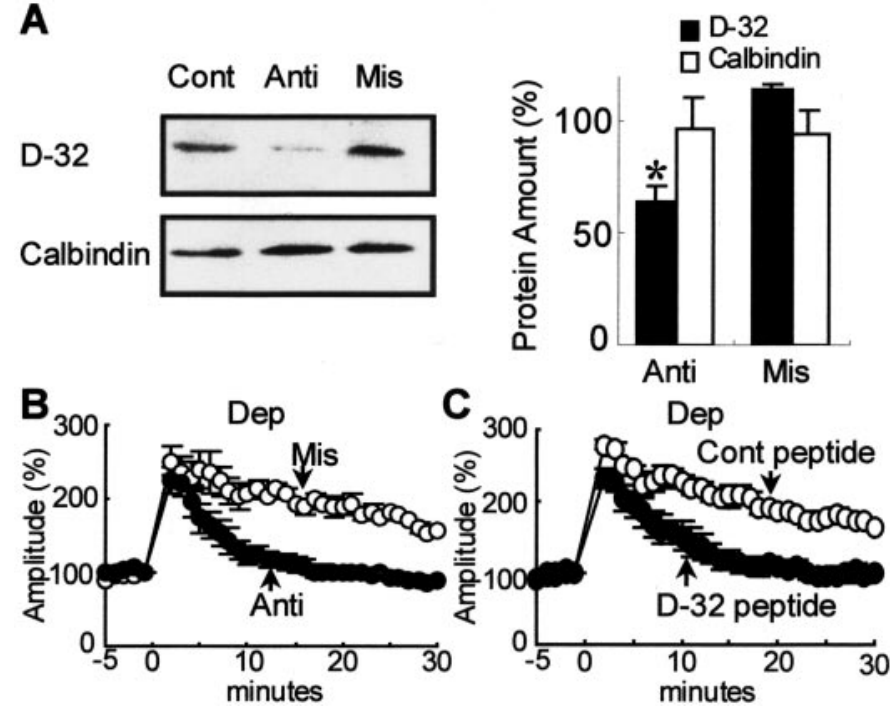

Figure 5. Involvement of DARPP-32 in the regulation of RP. $A$, Western blotting of DARPP-32 after $8 \mathrm{hr}$ treatment with ODNs. Equal amounts of proteins $(50 \mu \mathrm{g})$ were prepared from cultured cells and applied to each lane. Relative amounts of DARPP-32 revealed by Western blotting after $8 \mathrm{hr}$ treatment with ODNs are also presented $(n=5)$. The densities of bands are normalized. The value of untreated control was assigned to $100 \%$. Significant difference $(p<0.01)$ was detected between the antisense-treated culture and the control (*). $B$, Time course of GABA response amplitude after the $8 \mathrm{hr}$ treatment with antisense $(\bullet)$ or missense (O) ODN. Conditioning depolarization was applied at 0 min. $n=5$ for each. $C$, The time courses of GABA response amplitude before and after conditioning depolarization in the presence of either $\mathrm{N}$-terminal peptide of DARPP-32 $(\bullet)$ or control peptide $(\bigcirc) . n=5$ for each. Cont, Control; Anti, antisense; Mis, missense; Dep, depolarization.

DARPP-32 to PP-1 is crucial for the regulation of RP and that the increase in PP-1 activity is sufficient to suppress RP.

\section{CaMKII activity is suppressed by $\mathrm{GABA}_{B} R$ through PKA inhibition and PP-1 activity}

CaMKII becomes an active form independent of $\mathrm{Ca}^{2+}$ and calmodulin when its Thr286 is autophosphorylated, a process that is considered critical for hippocampal LTP (Fukunaga et al., 1993; Braun and Schulman, 1995; Blitzer et al., 1998; Giese et al., 1998; Soderling, 2000). PP-1 dephosphorylates Thr286 and inactivates CaMKII. We therefore investigated whether the amount of active CaMKII could be correlated with RP induction under varied test conditions. We performed immunocytochemistry using an antibody that specifically recognizes active CaMKII autophosphorylated at Thr286. Cultured cerebellar neurons were treated for $2 \mathrm{~min}$ with conditioning solution and were then washed for $3 \mathrm{~min}$, followed by fixation and subsequent staining of phospho-Thr286 CaMKII. We quantified the active CaMKII signal by calculating the average fluorescence intensity of Thr286phosphorylated CaMKII in PNs. We defined calbindin-positive regions as the area of PNs. Depolarization of cultured neurons by 2 min incubation in high $\mathrm{K}^{+}(50 \mathrm{~mm})$ solution containing SCH50911, a $\mathrm{GABA}_{\mathrm{B}} \mathrm{R}$ antagonist, increased Thr286phosphorylated CaMKII (Fig. 6). SCH50911 was used to inhibit potential $\mathrm{GABA}_{\mathrm{B}} \mathrm{R}$ activation by GABA released from depolarized presynaptic terminals in the high $\mathrm{K}^{+}$solution. In contrast, $\mathrm{GABA}_{\mathrm{B}} \mathrm{R}$ activation by baclofen, a $\mathrm{GABA}_{\mathrm{B}} \mathrm{R}$ agonist, inhibited the high $\mathrm{K}^{+}$-induced increase in Thr286-phosphorylated CaMKII (Fig. 6). These results suggest that $\mathrm{GABA}_{\mathrm{B}} \mathrm{R}$ activation inhibits CaMKII activity in a PN. The inhibitory effect of ba-
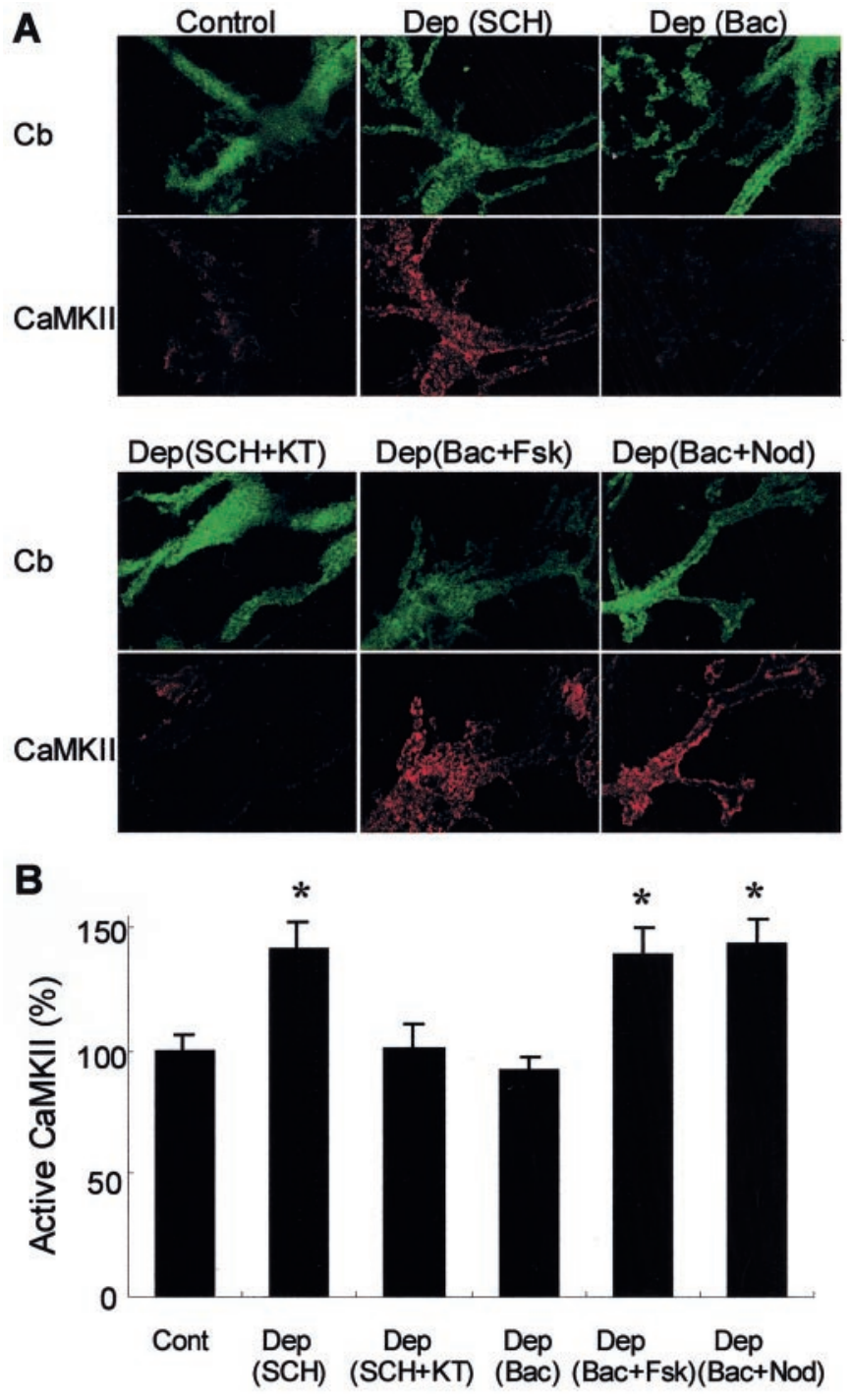

Figure 6. $\mathrm{GABA}_{\mathrm{B}} \mathrm{R}$ regulates depolarization-induced increase in active CaMKII through PKA inhibition and PP-1 activity. $A$, Immunocytochemistry against autophosphorylated $\mathrm{CaMKII}$ and calbindin $(\mathrm{Cb})$. Cultured neurons were treated with high $\mathrm{K}^{+}$solution in the presence of SCH50911 (SCH), baclofen (Bac), SCH50911 and KT5720 $(S C H+K T)$, baclofen and forskolin $(B a c+F s k)$, or baclofen and nodularin $(B a c+N o d)$. Scale bar, $10 \mu \mathrm{m}$. B, Relative amount of active CaMKII after each conditioning. The mean fluorescent intensity of active CaMKII in PNs was normalized. The value of untreated control was assigned to $100 \%$. Compared with the control, significant difference $(p<0.01$; Student's $t$ test) was detected in $S C H, B a c+F s k$, and Bac+Nod.

clofen on the depolarization-induced CaMKII autophosphorylation was mimicked by the PKA inhibitor KT5720 (Fig. 6). Forskolin, an adenylyl cyclase activator, abolished the inhibitory effect of baclofen on Thr286-phosphorylation of CaMKII induced by depolarization (Fig. 6), suggesting that $\mathrm{GABA}_{\mathrm{B}} \mathrm{R}$-dependent CaMKII inhibition is mediated by PKA inhibition through inhibition of adenylyl cyclase. Furthermore, nodularin, a PP-1 inhibitor, prevented the inhibition of CaMKII autophosphorylation by baclofen (Fig. 6), indicating that $\mathrm{GABA}_{\mathrm{B}} \mathrm{R}$ inhibits CaMKII through PP-1. Immunofluorescent staining with an antibody that recognizes both autophosphorylated and nonphosphorylated CaMKII showed that none of the conditioning treatments affected the total amount of CaMKII in PNs (data not shown). 


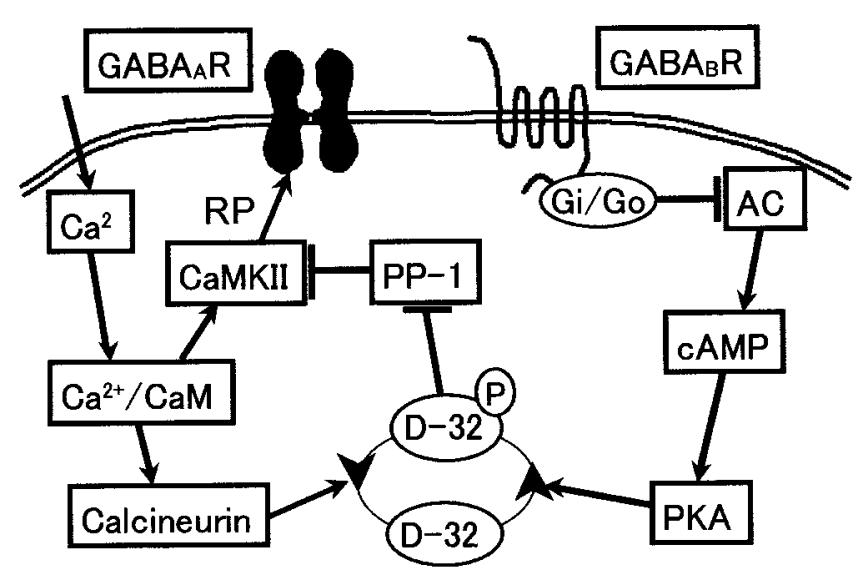

Figure 7. A model for the signaling cascades regulating RP induction and suppression. CaM, Calmodulin; $D$-32, DARPP-32; $P$, phosphate; $A C$, adenylyl cyclase.

Thus, these results indicate that $\mathrm{GABA}_{\mathrm{B}} \mathrm{R}$ activation during depolarization of a PN inhibits CaMKII autophosphorylation at Thr286 through PKA inhibition and PP-1 activity and that the amount of autophosphorylated CaMKII is large whenever RP is induced. Thus, CaMKII activity seems crucial for RP induction.

\section{DISCUSSION}

\section{Signaling cascades regulating RP induction and suppression}

We have studied the signaling cascades regulating the induction of RP, a form of long-lasting synaptic plasticity at inhibitory synapses on cerebellar PNs (Kano et al., 1992). Involvement of CaMKII and PKA in RP induction has been reported previously (Kano et al., 1996; Kawaguchi and Hirano, 2000). Here we have shown that inhibition of PP-1 or calcineurin blocks the suppression of RP. Furthermore, we have demonstrated that PP-1 is located downstream of PKA and upstream of CaMKII within the signaling cascade. Our results also indicate that DARPP-32 is implicated in the regulation of RP. Despite a relatively small reduction of DARPP-32, the impairment of RP induction was observed in all antisense ODN-treated PNs. This result might imply that RP induction is tightly regulated by PP-1 activity controlled by DARPP-32, which integrates the activities of both calcineurin and PKA. Immunocytochemistry of active CaMKII autophosphorylated at Thr286 supports the idea that CaMKII activity is regulated by $\mathrm{GABA}_{\mathrm{B}} \mathrm{R}$, PKA, calcineurin, and PP-1. Taken together, these data suggest that the following signaling cascades regulate the $\mathrm{GABA}_{\mathrm{A}}$ response in a PN (Fig. 7).

Intracellular $\mathrm{Ca}^{2+}$ increase during depolarization leads to formation of a $\mathrm{Ca}^{2+} /$ calmodulin $\left(\mathrm{Ca}^{2+} / \mathrm{CaM}\right)$ complex, which activates $\mathrm{CaMKII}$ and calcineurin. The activated CaMKII then induces RP, whereas the activated calcineurin creates a negativefeedback loop to suppress CaMKII activity by dephosphorylating DARPP-32, thus releasing PP-1 from inhibition. In the absence of GABAergic input, however, the basal PKA activity phosphorylates DARPP-32 and counteracts the calcineurin activity. Thus, most of the PP-1 is inhibited by phosphorylated DARPP-32 inducing RP through CaMKII activation during postsynaptic depolarization. When $\mathrm{GABA}_{\mathrm{B}} \mathrm{R}$ is activated during the depolarization, PKA activity is reduced, allowing calcineurin to dephosphorylate most of DARPP-32. The dephosphorylated DARPP-32 in turn releases active PP-1, resulting in CaMKII inhibition and
RP suppression. PP-1 might also dephosphorylate the substrate proteins of CaMKII, countering the latter's RP induction activity.

The mechanism by which CaMKII induces RP remains to be elucidated. Phosphorylation of $\mathrm{GABA}_{\mathrm{A}} \mathrm{R}$ by $\mathrm{CaMKII}$ has been reported previously (MacDonald and Moss, 1994). RP might be induced by CaMKII activation through direct phosphorylation of $\mathrm{GABA}_{\mathrm{A}} \mathrm{R}$, which might increase its affinity for GABA, increase the single channel conductance, or increase the open time of the $\mathrm{Cl}^{-}$channel of the GABA $\mathrm{A}$ (Moss and Smart, 1996; Smart, 1997). Another possibility is an increase in surface expression of postsynaptic receptors, as demonstrated in excitatory glutamatergic synapses (Hayashi et al., 2000). Phosphorylation might influence the subcellular localization of receptors, including the number of receptors on the cell membrane. Although we could not detect any changes in the amplitude or time course of mIPSC through the inhibition of PP-1, calcineurin, PKA, or CaMKII, it was reported that the time course of IPSC in the cultured hippocampal neuron was shortened by calcineurin inhibition (Jones and Westbrook, 1997). The differential effect of calcineurin inhibition on the IPSC might be caused by a difference in subunit composition of $\mathrm{GABA}_{\mathrm{A}}$ receptors or in molecules interacting with $\mathrm{GABA}_{\mathrm{A}}$ Rs.

We note that the RP that we observed may not be a single process. GABA application coupled with depolarization did not suppress the earlier potentiation (0-10 min) completely. Kinase inhibitors (KN62 and KT5720), DARPP-32 peptide, and antisense ODN-treatment did not suppress the earlier potentiation. Therefore, RP might consist of an early and a late phase, the induction mechanisms of which may differ. In this study we have focused only on the late phase of RP.

In the present model, we assume a relatively high basal activity of PKA in a PN, on the basis of our observation that the basal PKA activity is sufficient for the CaMKII-mediated RP induction. Given this assumption, there should be some mechanism to maintain the relatively high basal concentration of intracellular cAMP in a PN. A number of metabotropic receptors for various transmitters such as amines or glutamate are likely to contribute to the regulation of cAMP concentration in a PN. For example, it was reported that the extracellular $\mathrm{Ca}^{2+}$-activated metabotropic glutamate receptor mGluR1 activates adenylyl cyclase through direct coupling to the $\mathrm{G}_{\mathrm{s}}$-protein and increases cAMP concentration (Miyashita and Kubo, 2000). mGluR1 is expressed in PNs and implicated in cerebellar LTD, another form of synaptic plasticity at glutamatergic synapses on PNs (Aiba et al., 1994; Conquet et al., 1994; Shigemoto et al., 1994).

\section{Similarity of signaling cascades in RP regulation and LTP/LTD regulation}

It has been suggested that the CaMKII and calcineurin/I-1/PP-1 pathways are involved in the regulation of LTP and LTD at excitatory glutamatergic synapses in the hippocampal CA1 region (Malenka, 1994; Malenka and Nicoll, 1999; Lisman and Zhabotinsky, 2001). The function of AMPA-type glutamate receptors is regulated by phosphorylation and dephosphorylation. Lee et al. (2000) proposed that Ser831 is phosphorylated by CaMKII during LTP, whereas S845, which is phosphorylated by PKA in the basal state, is dephosphorylated by PP-1/2A during LTD. When the $\mathrm{Ca}^{2+}$ concentration increases to a high level in the CA1 neuron, CaMKII and $\mathrm{Ca}^{2+} / \mathrm{CaM}$-dependent adenylyl cyclase (type 1 or 8 ) are activated (Cooper et al., 1995; Wong et al., 1999). The latter activates PKA to phosphorylate I-1, which then 
inhibits PP-1, resulting in the activation of CaMKII (Blitzer et al., 1995, 1998; Makhinson et al., 1999; Allen et al., 2000; Otmakhova et al., 2000). On the other hand, a moderate increase in the intracellular $\mathrm{Ca}^{2+}$ concentration preferentially activates calcineurin. In the latter case, most of the I-1 is dephosphorylated so that active PP-1 is released, resulting in CaMKII inhibition and subsequent induction of LTD (Malenka, 1994; Mulkey et al., 1994). Thus, similar molecules are implicated in the regulation of synaptic plasticity at both excitatory and inhibitory synapses, but the mechanism of regulation by those molecules is different in the two cases.

The distinct regulation of synaptic plasticity at each synapse, switching between LTP and LTD (dependent on the frequency of homosynaptic activation) at a CA1 excitatory synapse, and gating of RP induction (dependent on the presence or absence of homosynaptic activation during postsynaptic depolarization) at a cerebellar inhibitory synapse, might be caused by differences in the molecules expressed and by a difference in the basal cAMP level in each postsynaptic neuron. $\mathrm{Ca}^{2+} / \mathrm{CaM}$-activated adenylyl cyclase and I-1 are expressed in CA1 pyramidal neurons but not in PNs, whereas DARPP-32 is expressed in PNs but not in CA1 neurons. In CA1 neurons, glutamate receptors are modulated, whereas in PNs, GABA $\mathrm{A}_{\mathrm{A}} \mathrm{R}$ are modulated. The difference in regulation of adenylyl cyclase between the two neurons, activation by $\mathrm{Ca}^{2+} / \mathrm{CaM}$ in $\mathrm{CA} 1$ and inhibition by $\mathrm{GABA}_{\mathrm{B}} \mathrm{R}$ activity in PNs, may be crucial. DARPP-32 is expressed predominantly in neurons receiving dopaminergic inputs (Hemmings et al., 1984; Greengard et al., 1999) and plays a critical role in dopamine signaling and switching between LTP and LTD induction in the striatum (Calabresi et al., 2000). The signaling cascade regulating CaMKII activity through the calcineurin/DARPP-32 (I-1)/PP-1 pathway might be implicated in the regulation of various forms of synaptic plasticity in the CNS.

\section{REFERENCES}

Aiba A, Kano M, Chen C, Stanton ME, Fox GD, Herrup K, Zwingman TA, Tonegawa S (1994) Deficient cerebellar long-term depression and impaired motor learning in mGluR1 mutant mice. Cell 7:377-388.

Allen PB, Hvalby O, Jensen V, Errington ML, Ramsay M, Chaudhry FA, Bliss TV, Storm-Mathisen J, Morris RG, Andersen P, Greengard P (2000) Protein phosphatase-1 regulation in the induction of long-term potentiation: heterogeneous molecular mechanisms. J Neurosci 20:3537-3543.

Blitzer RD, Wong T, Nouranifar R, Iyengar R, Landau EM (1995) Postsynaptic cAMP pathway gates early LTP in hippocampal CA1 region. Neuron 15:1403-1414.

Blitzer RD, Connor JH, Brown GP, Wong T, Shenolikar S, Iyengar R, Landau EM (1998) Gating of CaMKII by cAMP-regulated protein phosphatase activity during LTP. Science 280:1940-1942.

Braun AP, Schulman H (1995) The multifunctional calcium/ calmodulin-dependent protein kinase: from form to function. Annu Rev Physiol 57:417-445.

Calabresi P, Gubellini P, Centonze D, Picconi B, Bernardi G, Chergui K, Svenningsson P, Fienberg AA, Greengard P (2000) Dopamine and cAMP-regulated phosphoprotein $32 \mathrm{kDa}$ controls both striatal longterm depression and long-term potentiation, opposing forms of synaptic plasticity. J Neurosci 20:8443-8451.

Conquet F, Bashir ZI, Davies CH, Daniel H, Ferraguti F, Bordi F, Franz Bacon K, Reggiani A, Matarese V, Conde F (1994) Motor deficit and impairment of synaptic plasticity in mice lacking mGluR1. Nature 372:237-243.

Cooper DM, Mons N, Karpen JW (1995) Adenylyl cyclases and the interaction between calcium and cAMP signalling. Nature 374:421424.

Ehrlich ME, Kurihara T, Greengard P (1990) Rat DARPP-32: cloning, sequencing, and characterization of the cDNA. J Mol Neurosci 2:1-10.

Fukunaga K, Stoppini L, Miyamoto E, Muller D (1993) Long-term potentiation is associated with an increased activity of $\mathrm{Ca} 2+1$ calmodulin-dependent protein kinase II. J Biol Chem 268:7863-7867.

Giese KP, Fedorov NB, Filipkowski RK, Silva AJ (1998) Autophosphorylation at Thr286 of the alpha calcium-calmodulin kinase II in LTP and learning. Science 279:870-873.
Greengard P, Allen PB, Nairn AC (1999) Beyond the dopamine receptor: the DARPP-32/protein phosphatase-1 cascade. Neuron 23:435447.

Hansel C, Linden DJ, D'Angelo E (2001) Beyond parallel fiber LTD: the diversity of synaptic and non-synaptic plasticity in the cerebellum. Nat Neurosci 4:467-475.

Hashimoto T, Ishii T, Ohmori $\mathrm{H}$ (1996) Release of $\mathrm{Ca}^{2+}$ is the crucial step for the potentiation of IPSCs in the cultured cerebellar Purkinje cells of the rat. J Physiol (Lond) 497:611-627.

Hayashi Y, Shi SH, Esteban JA, Piccini A, Poncer JC, Malinow R (2000) Driving AMPA receptors into synapses by LTP and CaMKII: requirement for GluR1 and PDZ domain interaction. Science 287:2262-2267.

Hemmings Jr HC, Greengard P, Tung HY, Cohen P (1984) DARPP-32, a dopamine-regulated neuronal phosphoprotein, is a potent inhibitor of protein phosphatase-1. Nature 310:503-505.

Hirano T, Kasono K (1993) Spatial distribution of excitatory and inhibitory synapses on a Purkinje cell in a rat cerebellar culture. J Neurophysiol 70:1316-1325.

Ingebritsen TS, Cohen P (1983) Protein phosphatases: properties and role in cellular regulation. Science 221:331-338.

Ito M (2001) Cerebellar long-term depression: characterization, signal transduction, and functional roles. Physiol Rev 81:1143-1195.

Jones MV, Westbrook GL (1997) Shaping of IPSCs by endogenous calcineurin activity. J Neurosci 17:7626-7633.

Kano M (1995) Plasticity of inhibitory synapses in the brain: a possible memory mechanism that has been overlooked. Neurosci Res 21: $177-182$.

Kano M, Konnerth A (1992) Potentiation of GABA-mediated currents by cAMP-dependent protein kinase. NeuroReport 3:563-566.

Kano M, Rexhausen U, Dreessen J, Konnerth A (1992) Synaptic excitation produces a long-lasting rebound potentiation of inhibitory synaptic signals in cerebellar Purkinje cells. Nature 356:601-604.

Kano M, Kano M, Fukunaga K, Konnerth A (1996) Ca(2+)-induced rebound potentiation of gamma-aminobutyric acid-mediated currents requires activation of $\mathrm{Ca}^{2+} /$ calmodulin-dependent kinase II. Proc Natl Acad Sci USA 93:13351-13356.

Kawaguchi S, Hirano T (2000) Suppression of inhibitory synaptic plasticity by presynaptic activity through postsynaptic $\mathrm{GABA}_{\mathrm{B}}$ receptors in Purkinje neuron. Neuron 27:339-347.

Komatsu Y (1996) GABA $_{\mathrm{B}}$ receptors, monoamine receptors, and postsynaptic inositol trisphosphate-induced $\mathrm{Ca}^{2+}$ release are involved in the induction of long-term potentiation at visual cortical inhibitory synapses. J Neurosci 16:6342-6352.

Kwon YG, Huang HB, Desdouits F, Girault JA, Greengard P, Nairn AC (1997) Characterization of the interaction between DARPP-32 and protein phosphatase 1 (PP-1): DARPP-32 peptides antagonize the interaction of PP-1 with binding proteins. Proc Natl Acad Sci USA 94:3536-3541.

Lee HK, Barbarosie M, Kameyama K, Bear MF, Huganir RL (2000) Regulation of distinct AMPA receptor phosphorylation sites during bidirectional synaptic plasticity. Nature 405:955-959.

Lisman JE, Zhabotinsky AM (2001) A model of synaptic memory: a CaMKII/PP1 switch that potentiates transmission by organizing an AMPA receptor anchoring assembly. Neuron 31:191-201.

MacDonald BJ, Moss SJ (1994) Differential phosphorylation of intracellular domains of gamma-aminobutyric acid type A receptor subunits by calcium/calmodulin type 2-dependent protein kinase and cGMPdependent protein kinase. J Biol Chem 269:18111-18117.

Makhinson M, Chotiner JK, Watson JB, O’Dell TJ (1999) Adenylyl cyclase activation modulates activity-dependent changes in synaptic strength and $\mathrm{Ca} 2+/$ calmodulin-dependent kinase II autophosphorylation. J Neurosci 19:2500-2510.

Malenka RC (1994) Synaptic plasticity in the hippocampus: LTP and LTD. Cell 78:535-538.

Malenka RC, Nicoll RA (1999) Long-term potentiation: a decade of progress? Science 285:1870-1874.

Miyashita T, Kubo Y (2000) Extracellular Ca2+ sensitivity of mGluR1alpha induces an increase in the basal cAMP level by direct coupling with Gs protein in transfected CHO cells. Receptors Channels 7:77-91.

Moss SJ, Smart TG (1996) Modulation of amino acid-gated ion channels by protein phosphorylation. Int Rev Neurobiol 39:1-52.

Mulkey RM, Endo S, Shenolikar S, Malenka RC (1994) Involvement of a calcineurin/inhibitor-1 phosphatase cascade in hippocampal longterm depression. Nature 369:486-488.

Nusser Z, Hajos N, Somogyi P, Mody I (1998) Increased number of synaptic GABA(A) receptors underlies potentiation at hippocampal inhibitory synapses. Nature 395:172-177.

Oda Y, Kawasaki K, Morita M, Korn H, Matsui H (1998) Inhibitory 
long-term potentiation underlies auditory conditioning of goldfish escape behavior. Nature 394:182-185.

Otmakhova NA, Otmakhov N, Mortenson LH, Lisman JE (2000) Inhibition of the cAMP pathway decreases early long-term potentiation at CA1 hippocampal synapses. J Neurosci 20:4446-4451.

Schalling M, Djurfeldt M, Hokfelt T, Ehrlich M, Kurihara T, Greengard P (1990) Distribution and cellular localization of DARPP-32 mRNA in rat brain. Brain Res Mol Brain Res 7:139-149.

Shigemoto R, Abe T, Nomura S, Nakanishi S, Hirano T (1994) Antibodies inactivating mGluR1 metabotropic glutamate receptor block longterm depression in cultured Purkinje cells. Neuron 12:1245-1255.

Smart TG (1997) Regulation of excitatory and inhibitory neuro- transmitter-gated ion channels by protein phosphorylation. Curr Opin Neurobiol 7:358-367.

Soderling TR (2000) CaM-kinases: modulators of synaptic plasticity. Curr Opin Neurobiol 10:375-380.

Strack S, Barban MA, Wadzinski BE, Colbran RJ (1997) Differential inactivation of postsynaptic density-associated and soluble $\mathrm{Ca} 2+/$ calmodulin-dependent protein kinase II by protein phosphatases 1 and 2A. J Neurochem 68:2119-2128.

Wong ST, Athos J, Figueroa XA, Pineda VV, Schaefer ML, Chavkin CC, Muglia LJ, Storm DR (1999) Calcium-stimulated adenylyl cyclase activity is critical for hippocampus-dependent long-term memory and late phase LTP. Neuron 23:787-798. 